\title{
ARTIGOS
}

\section{COMPARAÇÃO DO PARASITISMO DA VEIA CENTRAL DA SUPRA-RENAL COM O DE OUTROS TECIDOS EM CHAGÁSICOS CRÔNICOS}

\author{
Vicente de Paula Antunes Teixeira, Marlene Antônia dos Reis, \\ Maria Betânia Mahler Araújo, Suzana Aparecida Silveira, \\ Lucelena dos Reis e Hipolito de Oliveira Almeida
}

\begin{abstract}
Através da análise morfológica e morfométrica de cortes seriados foi estudada a ocorrência de ninhos de $\mathbf{T}$. cruzi na veia central e no parênquima das supra-renais, no miocárdio ventricular esquerdo e na veia cava inferior de chagásicos crônicos. Em 36 casos estudados, 50\% apresentavam fleboparasitismo supra-renálico (total 29 ninhos); 3,1\% apresentavam parasitismo na veia cava (apenas 1 ninho) e em 16,8\% dos casos encontramos miocardiócitos parasitados (total 23 ninhos). A densidade de parasitismo, expressa em número de ninhos por $100 \mathrm{~mm}^{2}$ de tecido examinado, foi de 0,585 para a veia supra-renálica, de 0,001 para a veia cava e 0,01 para o miocárdio. Em 269.103,1 $\mathrm{mm}^{2}$ de parênquima supra-renálico não encontramos nenhum ninho. Embora tenha sido a menor área examinada, a veia central apresentou a maior freqüencia de ninhos de $\mathrm{T}$. cruzi. Como a diferenca básica entre estes tecidos está na riqueza de corticóides no sangue que nutre a veia central, podemos admitir que esta prevaléncia talvez seja devido ao ambiente hormonal, que por seu efeito imunossupressor e anti-inflamatório favoreceria a sobrevida dos parasitas. de Chagas.

Palavras-chaves: Supra-renal. Veia cava inferior. Miocárdio. Trypanosoma cruzi. Doenca
\end{abstract}

Nos últimos anos descrevemos a existência de células musculares lisas na veia central das suprarenais parasitadas pelo $T$. cruzi $i^{4}$, o que foi confirmado por Barbosa Jr. e Andrade9. A literatura sobre a doença de Chagas crônica humana, anterior aos estudos citados acima, registra apenas as referências ao parasitismo pelo $T$. cruz $i$ em células da cortical das supra-renais, feitas por Chagas $12 \quad 13 \quad 14 \quad 15 \quad 16 \quad 17$, geralmente citando observações de Vianna ${ }^{43}$.

Em trabalho posterior ${ }^{39}$ mostramos ainda que $55 \%$ dos chagásicos crônicos falecidos em decorrência de insuficiência cardíaca congestiva (ICC) apresentavam leiomiócitos da veia central da supra-renal parasitados pelo $T$. cruzi $i$. Embora esta cifra seja bastante superior ao que a literatura registra sobre $o$ encontro de parasitas no miocárdio 82344 (de 30 a $55 \%$ para a veia supra-renálica e de 18 a $36 \%$ para o coração), esta diferença pode não ser real por duas razões básicas: a) Os chagásicos nos quais se estudaram as supra-renais e o miocárdio são diferentes e residiam em locais diversos, por isso as divergências entre nossos dados para as supra-renais e os de Koberle 23 ; Widmer e Azevedo 44 ; Andrade e Andra$\mathrm{de}^{8}$ para o miocárdio podem ser interpretadas como

Trabalho da Disciplina de Patologia Geral, Faculdade de Medicina do Triângulo Mineiro, Uberaba, MG.

Endereço para correspondência: Prof. Vicente de Paula Antunes Teixeira. Disciplina de Patologia Geral/FMTM. Pça. Manoel Terra s/n, 38100 Uberaba, MG.

Recebido para publicação em 13/12/90. devido a comportamentos variáveis das populações de chagásicos no que se refere à ocorrência de parasitas no seu organismo; b) nossa experiência tem mostrado que a quantidade de tecido examinado influi decisivamente na freqüencia do parasitismo, o que pode ser facilmente compreendido quando se leva em conta que a intensidade do parasitismo dos tecidos no chagásico crônico é, geralmente, baixa, exigindo, às vezes, o exame de centenas de cortes para o encontro de uma única célula parasitada.

Tentando esclarecer tais questões procuramos, em um mesmo grupo de chagásicos crônicos, comparar a freqüência e a intensidade do parasitismo no parênquima e na veia supra-renálica com o no miocárdio, nos valendo de métodos histométricos. Além disso, utilizando a mesma metodologia estudamos o parasitismo da parede da veia cava, para avaliar eventual tropismo para tecido muscular venoso com concentração mais baixa de hormônios supra-renálicos.

\section{MATERIAL E MÉTODOS}

O material para estudo foi proveniente de necrópsias completas de 36 chagásicos crônicos, realizadas na Disciplina de Patologia Geral da Faculdade de Medicina do Triângulo Mineiro (Uberaba, MG), que apresentavam as reações de Guerreiro-Machado, de imunofluorescência indireta e de hemaglutinação positivas para $T$. cruzi. Esta população era constituida por 26 homens e 10 mulheres, com idades entre 23 e 75 anos. Os materiais colhidos foram 
Teixeira VPA, Reis MA, Araújo MBM, Silveira SA, Reis L, Almeida Ho. Comparafāo do parasitismo da veia central da supra-renal como de outros tecidos em chagásicos crônicos. Revista da Sociedade Brasileira de Medicina Tropical 24: 73-78, abrjun, 1991

fixados em formol comercial a $10 \%$, por tempo nunca inferior a 48 horas, após o que, as supra-renais e o coração foram pesados. Das supra-renais retiramos de 8 a 15 secções transversais e dos corações retiramos um fragmento retangular da parede do ventrículo esquerdo, junto ao terço médio da margem obtusa. Colhemos também em 32 destas necropsias, um fragmento anular da veia cava inferior, com cerca de $0,5 \mathrm{~cm}$ de espessura, no segmento imediatamente a jusante da confluência da veia central da supra-renal direita. Estes fragmentos foram desidratados em álcoois em concentrações crescentes, chegando até o absoluto, diafanizados em xilol, incluidos em parafina a quente e confeccionados blocos.

Através de microtomia seriada, para cada caso, obtivemos cortes de $6 \mu \mathrm{m}$, sendo 300 a 400 para as supra-renais; 100 para o coração e 100 para a veia cava inferior. Estes foram corados de maneira intercalada (um sim, outro não), pela hematoxilina-eosina; a seguir foram levados ao microscópio óptico para cuidadosa pesquisa de ninhos do $T$. cruzi na veia central, no parênquima da supra-renal, no miocárdio e na veia cava inferior. Foram anotados a freqüência de casos com parasitas e o número de ninhos de amastigotas por caso, sendo a primeira avaliada estatisticamente através do teste do $\mathrm{X}^{2}$. Ütilizando uma câmara clara, acoplada a lupa, desenhamos as várias secções da veia cava e das supra-renais, sendo que nestas foram tomadas separadamente as áreas do parênquima (cortical e medular) e da parede da veia central. Posteriormente, com auxílio de um planímetro de compensação medimos a área. Sendo os cortes de miocárdio retangulares e facilmente delimitados a "olho nu", sua área foi obtida a partir da medida de seus lados com um paquímetro de precisão. Através do número de ninhos de $T$. cruzi e da área obtida para cada tecido examinado, calculamos a densidade do parasitismo, que foi expressa em números de ninhos por $100 \mathrm{~mm}^{2}$ de superficie de corte histológico.

\section{RESULTADOS}

A cortical da supra-renal apresentou em $58,8 \%$ dos casos infiltrado inflamatório, geralmente focal e discreto, constituído por mononucleares, em especial do tipo pequeno linfócito. $\mathrm{Na}$ medular os infiltrados foram mais freqüentes $(94,5 \%)$, sendo mais ricos em células da linhagem plasmocitária. Não encontramos ninhos de amastigotas no parênquima (cortical e medular) das supra-renais (Figura 1). A parede da veia central apresentou infiltrado mononuclear rico em plasmócitos, de intensidade variável, em $100 \%$ dos casos. Os ninhos na parede venosa serão descritos de maneira sumária, pelo fato de tal já ter sido feito com detalhes em trabalhos anteriores 1253940 . Encontramos ninhos (Figura 2) na musculatura venosa na

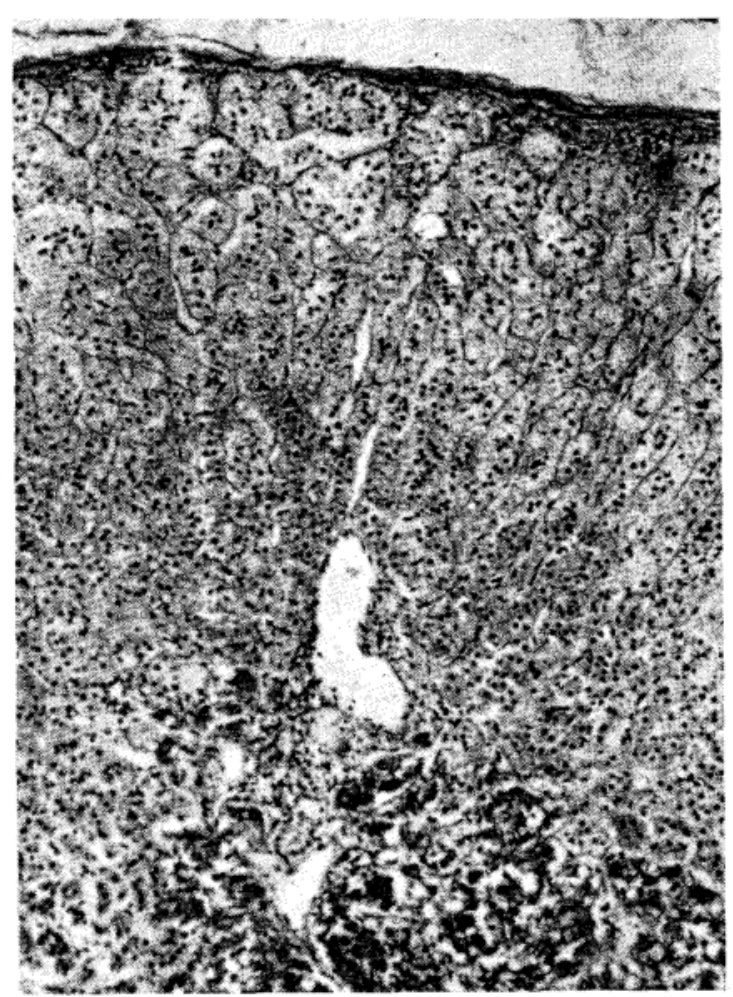

Figura 1 - Parênquima supra-renálico. Acima observa-se cápsula fibrosa, em seguida a camada cortical e embaixo a medular. Nota-se infiltrado discreto de mononucleares na juncâo córtico-medular e medular adjacente. Não se encontram parasitas (HEx80).

metade dos casos examinados, sendo que em cerca de $30 \%$ deles visualizamos núcleos geralmente de tamanho maior que o observado na fibra muscular lisa normal, com a forma freqüentemente atípica e corado mais intensamente. Em $71 \%$ dos ninhos não encontramos infiltrado leucocitário focal associado. $\mathrm{Na}$ maioria dos casos o número de ninhos variou de um a quatro, entretanto, em três casos o parasitismo foi maciço, com centenas de ninhos nos segmentos da veia central examinados.

Encontramos apenas um ninho na musculatura da veia cava, de forma ovóide, medindo $67,6 \times 30,3 \mu \mathrm{m}$ de diâmetros, apresentando núcleo excêntrico, picnótico, com 8,5 $\times 4,9 \mu$ m de diâmetros. Ñao havia infiltrado associado topograficamente a este ninho (Figura 3). Por outro lado, encontramos em $43,7 \%$ das cavas examinadas, infiltrados leucocitários, constituídos por pequenos linfócitos e raros plasmócitos na musculatura longitudinal da veia, de intensidade discreta ou moderada.

Encontramos seis casos $(16,8 \%)$ com parasitas no miocárdio, sendo um ninho de $T$. cruz $i$ em um caso (Figura 4), três ninhos em dois casos, quatro ninhos em um caso e seis ninhos em dois casos. A maioria 


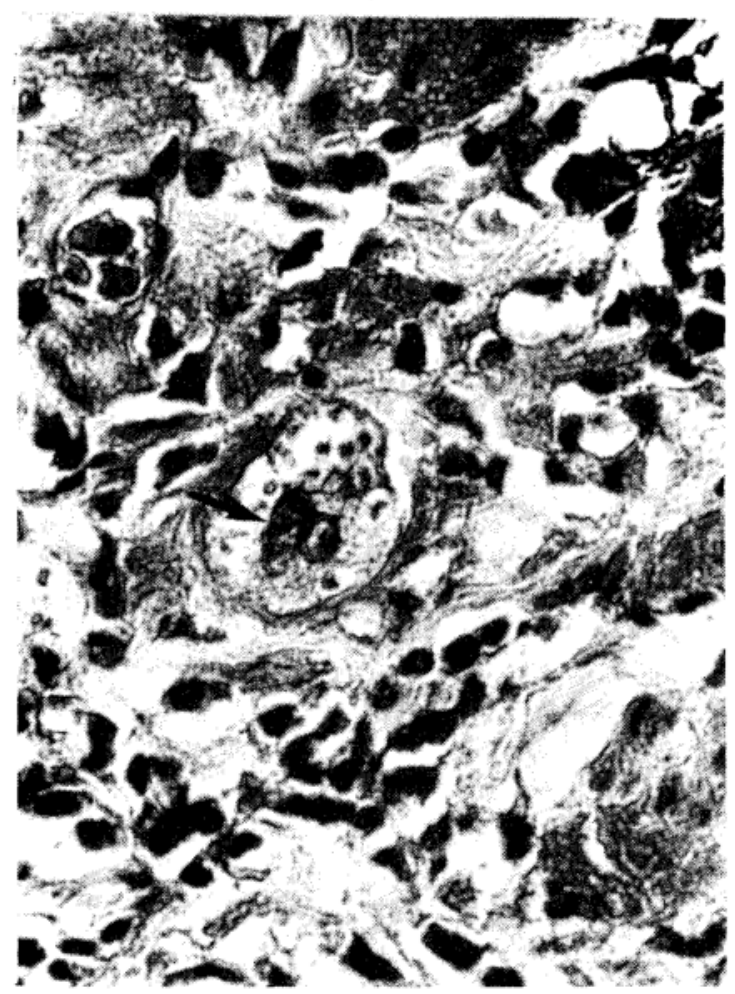

Figura 2-Ninho na veia central da supra-renal, localizado na intimidade de um fascículo musćular, apresentando núcleo volumoso, lobulado e hipercromático(seta). A célula está muito aumentada de volume e globosa (HEx640).

destes miocardiócitos parasitados (70\%) estava envolta por exsudato leucocitário de intensidade variável.

$\mathrm{Na}$ Tabela 1 observa-se um quadro geral do parasitismo na veia central e no parênquima (cortical e medular) da supra-renal, na parede da veia cava inferior e no miocárdio ventricular esquerdo.

\section{DISCUSSÃO}

$O$ presente trabalho demonstra que a veia central da supra-renal é o local de maior densidade de parasitismo pelo $T$. cruzi, quando comparada com o parânquima desta glândula, com a parede da veia cava inferior e com o miocárdio ventricular esquerdo.

A ausência de ninhos nas células corticais e medulares da supra-renal dos chagásicos crônicos está de acordo com os achados de Vianna ${ }^{43}$, o que, aparentemente, contraria as afirmações de Chagas que, em uma série de trabalhos 121314151617 , cita o parasitismo nesta sede. Aliás, é de um caso agudo estudado por Crowell ${ }^{19}$, o único relato de encontro e documentação fotográfica de ninho de $T$. cruzi na córtex supra-renal em humanos. A ausência de parasitas no parênquima cortical e medular pode indicar que

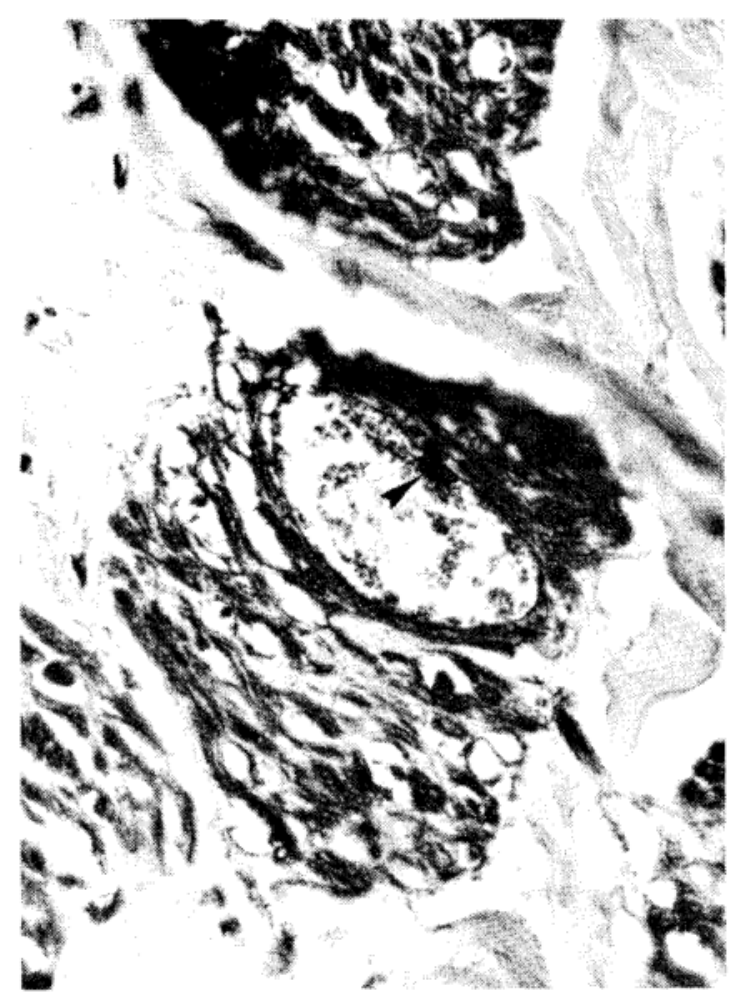

Figura 3 - Célula muscular lisa da veia cava-inferior parasitada pelo T. cruzi Observa-se um fascículo muscular cortado transversalmente, na intimidade do qual vếse o ninho de forma ovóide, com núcleo picnótico (seta) rechacado em direçāo a membrana citoplasmática. $A$ célula também está aumentada de volume e globosa (HEx500).

estas células não permitem a penetração do $T$. cruzi ou, em permitindo, não ofereçam condições propicias para manutenção intracelular na fase crônica da doença.

A baixa freqüência de chagásicos crônicos com ninho do $T$. cruzi na parede da veia cava contrasta com a ocorrência destes na veia supra-renálica, sendo esta diferença realçada quando se analisa a densidade do parasitismo. Como pode ser observado na Tabela 1 , para uma área total examinada de $4.957 \mathrm{~mm}^{2}$ de parede da veia supra-renálica de 33 chagásicos crônicos, sem parasitismo maciço, encontraram-se 29 ninhos de amastigotas, enquanto que em uma área 15 vezes maior $\left(73.319 \mathrm{~mm}^{2}\right)$ de parede de veia cava de 32 destes casos, encontrou-se apenas 1 ninho. Expressando estes números em ninhos por $100 \mathrm{~mm}^{2}$, verificamos que a densidade de ninhos de amastigotas na veia central da supra-renal foi 585 vezes maior que na veia cava inferior em um mesmo grupo de chagásicos crônicos. Os leiomiócitos apesar de semelhantes em ambas as veias, vivem em ambientes diferentes, uma vez que o interstício da veia supra-renálica realiza trocas com o sangue proveniente principalmente da cortical, o qual detém a maior concentração de 


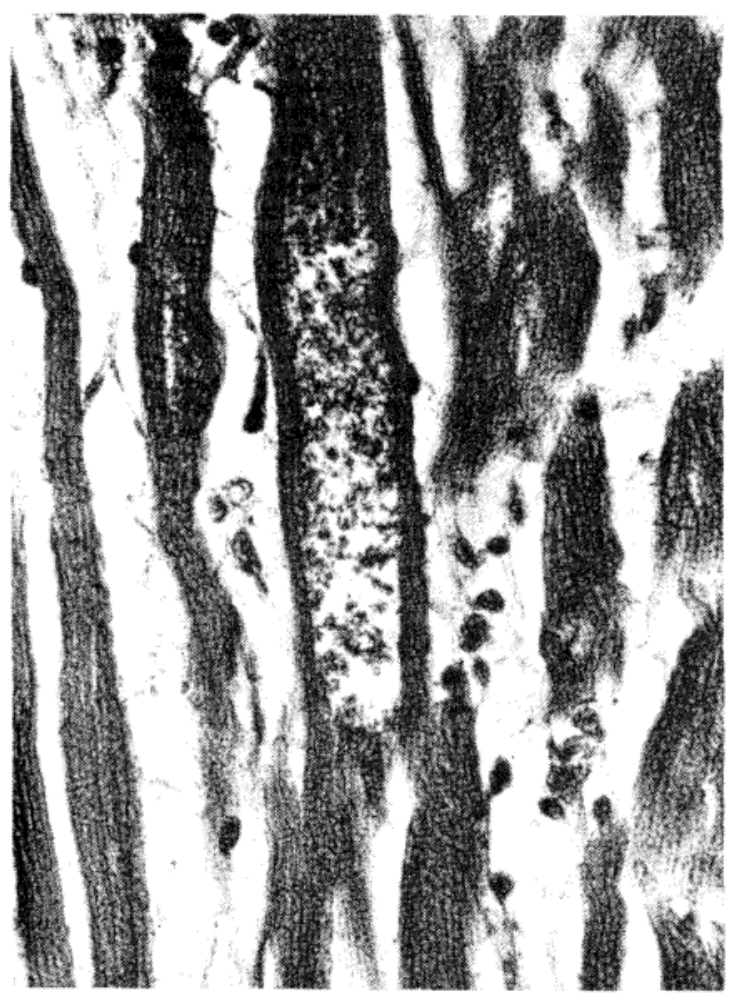

Figura 4 - Miocardiócito parasitado no ventrículo esquerdo. Ao contrário do que se observa nos leiomiócitos venosos, a forma da célula está mantida. O aumento do volume é muito discreto e uma orla de citoplasma miofibrilar é preservada, sem nenhum sinal de distorção (HEx500). corticóides do organismo, o que obviamente não ocorre na veia cava. Desta forma, o tropismo do $T$. cruz $i$ para as células musculares das duas veias possivelmente seja o mesmo, mas sua sobrevivência na veia supra-renálica deve ser favorecida pelo ambiente rico em corticóides.

Influência semelhante dos corticóides sobre a colonização de parasitas na supra-renal é também relatada para tuberculose, hanseniase, coccidioidomicose e histoplasmose $\mathrm{e}^{38}$.

O efeito local dos corticóides, inibindo os mecanismos antitripanosoma do hospedeiro parecenos, no momento, a melhor explicação para a nitida predileção do $T$. cruzi para a veia central da suprarenal, pois estes hormônios têm conhecidos efeitos anti-inflamatórios e imunossupressores ${ }^{28}$, exacerbando o parasitismo tecidual e a parasitemia nas fases aguda ou crônica da doença de Chagas humana 3213035 e experimental 7293133343637 . Além disso, tem sido demonstrado que as imunidades celular e humoral têm importante participação no controle do parasitismo 27 , e da inflamação, na doença aguda experimental182022 2442 .

Por outro lado, quando se compara a densidade de ninhos do $T$. cruzi na veia cava e no miocárdio ventricular esquerdo vê-se que este é mais parasitado, sugerindo que o $T$. cruzi tenha maior tropismo para o miocardiócito que para o leiomiócito venoso. Aliás, este grande tropismo é visível na fase aguda humana819252643 e experimental7811324243, quando o parasitismo miocárdico assume grandes proporções.

Tabela 1 - Freqüência de ninhos do T. cruzi em diferentes tecidos de chagásicos crônicos e sua densidade populacional, expressa em números de ninhos por $100 \mathrm{~mm}^{2}$ de superficie de corte histológico examinado.

$\begin{array}{lllcc}\begin{array}{l}\text { No de casos } \\ \text { examinados }\end{array} & \begin{array}{c}\text { Casos com } \\ \text { parasitas }\end{array} & \begin{array}{c}\text { Somatório } \\ \text { dos ninhos }\end{array} & \begin{array}{c}\text { Somatório da } \\ \text { área }\left(\mathrm{mm}^{2}\right) \text { de } \\ \text { tecido examinada }\end{array} & \begin{array}{c}\text { Densidade do } \\ \text { parasitismo em } \\ \text { número de } \\ \text { ninhos } / 100 \mathrm{~mm}^{2} \\ \text { de tecido }\end{array} \\ \end{array}$

\section{Veia central da}

supra-renal

36

$18(50,0 \%)$

29*

4.957,4*

$0,585^{\star}$

Parênquima glandular

da supra-renal

36

0

Veia cava inferior

32

36
0

$1(3,1 \%)$

$6(16,8 \%)$
269.103,1

$$
73.319,5
$$

$220.273,2$
0

0,001

0,010 - Para a veia central das supra-renais, o somatório dos ninhos encontrados, a densidade de ninhos e o somatório da área de tecido examinada,
tiveram seus valores calculados excluindo-se 3 casos com parasitismo maciço da musculatura lisa desta veia.

Comparação dos casos com parasitos

(1) Veia central $x$ veia cava: $X^{2}=18,48 ; p<0,005$

(2) Veia central $x$ miocárdio: $X^{2}=9,00 ; p<0,005$

(3) Veia cava $x$ miocárdio: $X^{2}=3,34 ; p<0,005$ 
Teixeira VPA, Reis MA, Araúio MBM, Silveira SA, Reis L, Almeida Ho. Comparafâa do parasitismo da veia central da supra-renal com o de outros tecidos em chagásicos crónicos. Revista da Sociedade Brasileira de Medicina Tropical 24: 73-78, abr-jun, 1991

Entretanto, na fase crônica da doença a densidade de ninhos no miocárdio e em outros órgãos tem acentuada redução. $O$ que deve ser conseqüente ao desenvolvimento de mecanismos imunitários bastante eficientes para manter baixo o parasitismo tissular e a parasitemia ${ }^{10}$.

Este fato está de acordo com o que está expresso na Tabela 1, onde podemos observar que para uma área total examinada de $4.957 \mathrm{~mm}^{2}$ de parede da veia central de chagásicos crónicos, sem parasitismo maciço, encontramos 29 ninhos de amastigotas, enquanto que em uma área 44 vezes maior $\left(220.273 \mathrm{~mm}^{2}\right)$ de miocárdio ventricular esquerdo, dos mesmos casos, encontramos 23 ninhos. Expressando estes números em ninhos por $100 \mathrm{~mm}^{2}$, a densidade de ninhos na veia central da supra-renal foi 58 vezes maior do que no miocárdio ventricular esquerdo, em um mesmo grupo de chagásicos crônicos. Estes resultados sugerem que na veia central o $T$. cruzi conseguiria escapar às defesas imunitárias da fase crônica da doença, tornando este local um reservatório do parasita no chagásico crônico. Nesta localização, o parasita conseguiria completar ciclos intracelulares, funcionando como fonte para perpetuá-los no organismo do chagásico após a fase aguda.

Aliás, as observações recentes de agudização da doença com alta parasitemia e intenso parasitismo miocárdico em chagásicos crônicos que receberam transplante cardíaco e imunossupressores 641 , de um lado confirmam a importancia das defesas imunitárias no controle do parasitismo e de outro lado mostram que alguma sede extracardíaca deve estar sendo fonte de reinfecção endógena pelo T. cruzi, uma vez que o tecido cardíaco do paciente é quase que totalmente extirpado.

\section{SUMMARY}

By morphological and morphometric analyses of serial sections the occurrence of $T$. cruzi nests in the central vein and in the parenchyma of adrenal glands, in the left ventricular wall and in the inferior vena cava wall in chronic Chagasic patients was studied. Of 36 cases $50 \%$ showed parasites in the adrenal central vein wall (total 29 nests), $3.1 \%$ showed parasites in the vena caval wall (only I nest) and $16,8 \%$ we found parasites in the myocardiocytes (total 23 nests). The density of parasites measured in the nests for each $100 \mathrm{~mm}^{2}$ of the tissue examined, was 0.585 for the adrenal vein, 0.001 for the vena cava and 0.01 for the myocardium. No nest was found in $269103.1 \mathrm{~mm}^{2}$ of adrenal parenchyma. Although the central vein area examined was smaller, it showed the largest frequency of $\mathrm{T}$. cruzi nests. Since a basic difference between these tissues is the great quantity of corticoids in the blood of the adrenal central vein, this prevalence may be because of this hormonal ambient, which with its immunosupressor and anti-inflammatory effects could help T. cruzi survival.
Key-words: Adrenal. Inferior vena cava. Myocardium. Trypanosoma cruzi. Chagas disease.

\section{REFERÊNCIAS BIBLIOGRÁFICAS}

1. Almeida HO, Barbosa AJA, Gobbi H, Reis MA, Teixeira VPA, Brandão MC. Leiomiócitos e miocardiócitos parasitados pelo Trypanosoma cruzi em chagásicos crônicos: estudo comparativo. Arquivos Brasileiros de Cardiologia 48:217-222, 1987.

2. Almeida HO, Martins E, Franciscon JU, Teixeira VPA, Barbosa AJA, Gobbi H, Reis MA. Caracteristicas das células parasitadas pelo Trypanosoma cruzi na parede da veia central das supra-renais de chagásicos crônicos. Revista da Sociedade Brasileira de Medicina Tropical 19:227-231, 1986.

3. Almeida HO, Tafuri, WL, Bogliolo L, Cunha JC. Parasitismo incomum do miocárdio e do esôfago em chagásico crônico portador de doença de Hodgkin e em uso de imunodepressores. Revista da Sociedade Brasileira de Medicina Tropical 8:117-121, 1974.

4. Almeida HO, Teixeira VPA, Oliveira ACF. Flebite com parasitismo em supra-renais de chagásicos crônicos. Arquivos Brasileiros de Cardiologia 36:341-344, 1981.

5. Almeida HO, Teixeira VPA, Reis MA, Franciscon JU, Martins E. Modificações nucleares em células parasitadas pelo Trypanosoma cruzi em chagásicos crônicos. Revista da Sociedade Brasileira de Medicina Tropical 20:147-152, 1987.

6. Amato Neto V, Campos R, Matsubara L, Uip DE, Moreira AAB, Souza HBWT. Avaliações parasitológicas em pacientes com doença de Chagas submetidos a transplante cardiaco. In: Resumos da IV Reuniäo Anual Sobre Pesquisa Aplicada em Doença de Chagas, Araxá p. 22, 1987.

7. Andrade SG, Macedo V. Tratamento combinado da doença de Chagas com Bayer 2502 e corticóide (estudo experimental e clínico). Revista do Instituto de Medicina Tropical de São Paulo 15:421-430, 1973.

8. Andrade ZA, Andrade SG. Patologia. In: Brener Z, Andrade ZA (ed) Trypanosoma cruzi e doença de Chagas. 1a edição, Guanabara Koogan, Rio de Janeiro p. 199-248, 1979.

9. Barbosa Jr AA. Andrade ZA. Identificaçāo do Trypanosoma cruzi nos tecidos extracardiacos de portadores de miocardite crônica chagásica. Revista da Sociedade Brasileira de Medicina Tropical 17:123-126, 1984.

10. Brener Z. O parasito: relaçōes hospedeiro-parasito. In: Brener, Z, Andrade ZA (ed) Trypanosoma cruzi e doença de Chagas, 1a edição, Guanabara-Koogan, Rio de Janeiro p. 1-41, 1979.

11. Chagas C. Nova tripanosomíase humana. Memórias do Instituto Oswaldo Cruz 1:159-218, 1909.

12. Chagas C. Aspecto clínico geral da nova entidade mórbida produzida pelo Schizotrypanum cruzi. BrazilMédico 24:263-265, 1910.

13. Chagas C. Nova entidade mórbita do homem. Resumo geral de estudos etiológicos e clínicos. Memórias do Instituto Oswaldo Cruz 3:219-274, 1911.

14. Chagas C. O mal de Chagas. Archivo da Sociedade de Medicina e Cirurgia de São Paulo 3:34-66, 1912. 
Teixeira VPA, Reis MA, Araújo MBM, Silveira SA, Reis L, Almeida Ho. Comparação do parasitismo da veia central da supra-renal com o de outros tecidos em chagásicos crônicos. Revista da Sociedade Brasileira de Medicina Tropical 24: 73-78, abr-jun, 1991

15. Chagas C. Clinical and anatomo-pathological aspects of american trypanosomiasis. New Orleans Medical and Surgical Journal, index 1919-1920, reprinted from Prensa Medica Argentina 3:125-127, 1916.

16. Chagas C. Processos patojenicos da tripanozomiase americana. Memórias do Instituto Oswaldo Cruz 8:5$36,1916$.

17. Chagas C. Descoberta do Trypanosoma cruzi e verificação da tripanozomiase americana. Retrospecto histó rico. Memórias do Instituto Oswaldo Cruz 15:67-76, 1922.

18. Costa SCG, Lagrande PH. Development of cell mediated immunity to flagellar antigens and acquired resistance to infection by Trypanosoma cruzi in mice. Memórias do Instituto Oswaldo Cruz 76:367-381, 1981.

19. Crowell BC. The acute form of American Trypanosomiasis: notes on its pathology, with autopsy report and observations on trypanosomiasis in animals. American Journal of Tropical Medicine 3:425-454, 1923.

20. Culbertson JT, Kolodny MH. Acquired immunity in rats against Trypanosoma cruzi. Journal of Parasitology 24:83-90, 1938.

21. França LCM, Fleury RN, Ramos Jr. HA, Lemos S, Melaragno Filho R, Pasternak J. Moléstia de Chagas crônica associada a leucemia linfática: ocorrência de encefalite aguda como alteração do estado imunitário. Arquivos de Neuro-Psiquiatria 27:59-66, 1969.

22. Hanson WL. Immune response and mechanisms of resistence in Trypanosoma cruzi. Pan American Health Organization, Scientific Publication 347:22-34, 1977.

23. Koberle F. Cardiopatia chagásica. O Hospital 53:311346, 1958.

24. Kolodny MH. Studies on age resistence against tripanosome infections. VII. The influence of age upon the immunological response of rats to infections with Trypanosoma cruzi. American Journal of Hygiene 31:1-80, 1940.

25. Lopes ER, Chapadeiro E, Tafuri WL, Prata A. Doença de Chagas. In: Lopes ER, Chapadeiro E, Raso P, Tafuri WL (ed) Bogliolo Patologia, 4! edição, Guanabara Koogan, Rio de Janeiro, p. 1047-1065, 1987.

26. Lopes ER, Tafuri WL, Bogliolo L, Almeida HO, Chapadeiro E, Raso P. Miocardite chagásica aguda humana (ganglionite subepicárdica; agressão à fibra cardíaca por linfócitos; relaçāo entre amastigotas e fibra muscular). Revista do Instituto de Medicina Tropical de São Paulo 19:301-309, 1977.

27. Madeira ED, Campos-Neto A. Cellular cytotoxicity of Trypanosoma cruzi mediated by different classes of antibody and by lectins. Brazilian Journal of Medical and Biological Research 18:207-215, 1985.

28. Merkow L, Pardo M, Epstein SM, Verney E, Sidransky H. Lisosomal stability during phagocitosis of Aspergillus flavus spores by alveolar macrophages of cortisonetreated mice. Science 160:79, 1968.

29. Nery-Guimarães F, Lage HA. Ação da cortisona e da betametasona na doença de Chagas experimental. $\mathrm{O}$ Hospital 77:119-132, 1970.

30. Nery-Guimarães F, Silva NN, Clausell DT, Mello AL, Rapone T, Snell T, Rodrigues N. Um surto epidêmico de doença de Chagas de provável transmissão digestiva, ocorrido em Teutonia (Estrela - Rio Grande do Sul). O Hospital 73: 1767-1804, 1968.

31. Okumura M, Décourt LV. Estudo de efeitos de administraçāo de drogas imunodepressoras sobre a moléstia de Chagas experimental. Revista do Hospital das Clínicas, Faculdade de Medicina de São Paulo 24:335-342, 1969.

32. Okumura M, França LCM, Corrêa Netto A. Comentários sobre a patogenia da moléstia de Chagas. Especial referência à infecçāo experimental em camundongos. Revista do Hospital das Clínicas, Faculdade de Medicina de São Paulo 18:151-164, 1963.

33. Pizzi T, Chemke J. Acción de la cortisona sobre la infection experimental de la rata por Trypanosoma cruzi. Biologica 21:3-30, 1955.

34. Pizzi T, Rubio M, Prager $R$, Silva $R$ Acción de la cortisona en la infection experimental por Trypanosoma cruzi. Boletin Chileno de Parasitologia 7:22-24, 1952.

35. Rassi A, Doles J, Cardoso VM, Silva OQ, Leite MSB. Aumento da parasitemia na fase crônica da doença de Chagas humana, na vigência de terapêutica corticosteróide. Arquivos Brasileiros de Cardiologia 23( supl):55, 1970.

36. Rubbio $M$. Influência del acetato de cortisona sobre la virulência y localización tissular de una nueva cepa de Trypanosoma cruzi. Estudio de la persistência de los cambios observados. Biologica 21:75-89, 1955.

37. Seneca $\mathrm{H}$, Wolf A. Trypanosoma cruzi infection in the Indian monkey. The American Journal of Tropical Medicine and Hygiene 4:1009-1014, 1955.

38. Sommers SC. Adrenal gland. In: Kissane JM, Anderson WAD (ed) Anderson's Pathology, 8th edition, CV Mosby, Saint Louis p. 1429-1450, 1985.

39. Teixeira VPA. Parasitismo da veia central da suprarenal em diferentes formas anátomo-clínicas da doença de Chagas. Tese de Mestrado, Faculdade de Medicina da Universidade Federal de Minas Gerais, Belo Horizonte, 1985.

40. Teixeira VPA, Fernandes PA, Brandão MC, Gobbi $H$, Reis MA, Almeida HO. Parasitismo incomum na veia central da supra-renal em chagásicos crônicos. Arquivos Brasileiros de Cardiologia 47:425-428, 1986.

41. Uip DE, Strabell TMV, Belotti G, Bocchi GA, Stolf N, Pileggi F, Jatene AD, Amato Neto V. Evolução clinica de pacientes com doença de Chagas submetidos a transplante cardiaco. In: Resumos da IV Reunião Anual Sobre Pesquisa Aplicada em Doença de Chagas, Araxá p. 24, 1987.

42. Valim EMA. Influência do bloqueio da imunidade humoral e papel desempenhado pela imunidade celular T-dependente, na evolução da cardite da fase aguda da doença de Chagas experimental. Tese de Mestrado, Faculdade de Medicina da Universidade de São Paulo, Ribeirão Preto, 1987.

43. Vianna G. Contribuição para o estudo da anatomia patológica da "Molestia de Carlos Chagas". Memórias do Instituto Oswaldo Cruz 3:276-294, 1911.

44. Widmer CG, Azevedo ES. Sexo do hospedeiro humano e o desenvolvimento de formas parasitárias do Trypanosoma cruzi no miocárdio. Revista do Instituto de Medicina Tropical de São Paulo 14:109-113, 1972. 